\title{
Cytotoxic and Antimetastasis Effect of Ethyl Acetate Fraction from Caesalpinia sappan L. on MCF-7/HER2 Cells
}

\author{
Riris Istighfari Jenie ${ }^{1}$, Sri Handayani ${ }^{1,2}$, Ratna Asmah Susidarti ${ }^{1}$, Zalinar Udin ${ }^{2}$, \\ Edy Meiyanto ${ }^{*}$ \\ ${ }^{1}$ Cancer Chemoprevention Research Center, Faculty of Pharmacy, Universitas Gadjah Mada, Indonesia \\ ${ }^{2}$ Research Center for Chemistry, Indonesian Institute of Sciences (LIPI), Indonesia
}

\begin{abstract}
Overexpression of HER2 in breast cancer cell is found on invasive breast cancer and correlated with worse prognosis. Caesalpinia sappan $L$ shows cytotoxic activity on various cancer cells. The goal of this research is to determine the cytotoxic activity and inhibition of migration and invasion of ethyl acetate fraction of Caesalpinia sappan L. (FEA) on HER2 overexpression-breast cancer cells (MCF-7/HER2). The MTT and flow cytometry assay showed that FEA revealed cytotoxic effect in a dose-dependent manner $\left(\mathrm{IC}_{50}=34 \pm 3.1 \mu \mathrm{g} / \mathrm{mL}\right)$ and induced apoptosis, $S$ and $\mathrm{G} 2 / \mathrm{M}$ phase accumulation. Wound healing assay, gelatin zymography and immunoblotting assay showed that FEA inhibited migration and suppressed MMP2, MMP9, HER2 and Racl protein level. Thus, ethyl acetate fraction of Caesalpinia sappan $L$. is potential to be developed on future research especially to treat metastatic breast cancer with HER2 overexpression.
\end{abstract}

Keywords: Ethyl acetate fraction of Caesalpinia sappan L, cytotoxic effect, migration and invasion, MCF-7/HER2 cells

\section{INTRODUCTIONS}

Several studies reveal the potential effect of Caesalpinia sappan $\mathrm{L}$. and its compounds for cancer treatment (Kim, et al., 2005; Laksmiani, et al., 2015; Nirmal, et al., 2015; Nurzijah, et al., 2012) due to its major compounds. Brazilin and brazilein isolated from Caesalpinia sappan L. inhibit cancer cell growth through inducing of cell cycle arrest and apoptosis on cancer cells (Kim, et al., 2012; Tao, et al., 2011, 2013). Moreover, brazilein also inhibit migration of cancer cells, MDAMB-231 (Hsieh, et al., 2013). Migration and invasion are the important processes in early step of metastasis event (Brooks, et al., 2010). Thus, Caesalpinia sappan L. shows a promising anticancer agent targeted on the inhibition of proliferation and metastasis.

The ErbB2/HER2 (epidermal growth factor receptor 2) is a member of the epidermal growth factor receptor (EGFR) that is observed abundant in many human cancers especially breast cancer and related with invasive, drug resistance and poor prognosis. ErbB2 is also believed as a biomarker for invasive breast cancer, hence a potential therapeutic target (Brix, et al., 2014). Once HER2 receptor activated, it transduces intraselluler signals through several signaling cascades, including MAPK and
NF- $\kappa \mathrm{B}$ activation to induce cells proliferation and migration (Knuefermann, et al., 2003; Merkhofer, et al., 2010). Overexpression HER2 increases maintaining of Src activation resulting in MAPK activation through Raf Kinase to activate cells proliferation. In other event, activation of $\mathrm{Src}$ together with p120 catenin (p120) and Vav2 activates small Rho-GTPase protein (Rac1,cdc42 and RhoA) and modulate cell migration (Johnson, et al., 2010). However, down regulation of Rac1 protein expression reduces the migration and invasion potential of cancer cells (Chen, et al., 2011). Hence, inhibition of HER2 mediatedsignaling pathways is essential to abrogate the proliferation and metastasis of HER2 overexpressing cancer cells.

\footnotetext{
*Corresponding author e-mail: meiyan_e@ugm.ac.id
} 
In our previous result showed that ethanolic extract of C. sappan performed inhibitory effect on MCF7 and 4T1 breast cancer cells (Handayani, et al., 2016). Ethanolic extract suggest to contain too many compounds, whereas, brazilin and brazilein as well as other major phenolic compounds thought to contribute significantly in the cytotoxic effect against cancer cells (Kim, et al., 2012, 2005; Laksmiani, et al., 2015; Nurzijah, et al., 2012).

It is well known that some phenolic compounds, including brazilein and brazilin, in ethanolic extract can be fractionated by ethyl acetate solvent to obtain a purified extract (Nirmal, et al., 2015). The purified extract is valuable to be used in phytomedical practices due to the more concentrated active compounds with less abundant material and easier to achieve chemically standard reliability. Therefore, the purpose of this research is to explore the effect of ethylacetate fraction of C. sappan on metastatic human breast cancer cells especially in HER2 overexpressed breast cancer cells focusing on its proliferation and migration.

\section{MATERIALS AND METHODS}

\section{Preparation of samples}

Dried heartwoods powder of Caesalpinia sappan L. was obtained from B2P2TOOT Tawangmangu, Indonesia. Dried powder was extracted in methanol to get methanol extract. The methanol extract was diluted by methanol: water $(4: 1)$ and then partitioned with hexane. The aqueous layer was fractioned with ethyl acetate and concentrated with vacuum rotary evaporator to get fraction of ethyl acetate (FEA).

\section{Cell culture}

MCF-7/HER2 and MCF-7/empty factor (MCF-7/Mock) cell line were kindly given from Prof.Dr. Yoshio Inouye through Prof. Dr. Mashashi Kawaichi (NAIST, Japan) and were cultured in $\mathrm{CO}_{2}$ incubator $\left(37^{\circ} \mathrm{C}\right)$ with Dulbecco's Modified Eagle Medium (DMEM) medium (Gibco) contained $10 \%$ Fetal Bovine Serum (Gibco), 1.5\% PenicillinStreptomycin (Gibco) and $0.5 \%$ fungizone (Gibco). MDAMD-231 cell line was kindly given from Prof. Dr. Mashashi Kawaichi (NAIST, Japan) and was cultured in non- $\mathrm{CO}_{2}$ incubator $\left(37^{\circ} \mathrm{C}\right)$ with $L-15$ medium (Sigma) contained 15\% Fetal Bovine Serum
(Gibco), 1.5\% Penicillin-Streptomycin (Gibco) and $0.5 \%$ fungizone (Gibco).

\section{Cytotoxic assay in single and combination of samples}

MCF-7/HER2 cells were seeded in 96-well plates with $10^{4}$ cells/well. After confluent, cells were treated with various concentration of treatment groups. After $24 \mathrm{~h}$ incubation, culture medium was removed and cells were washed in PBS (Sigma). Then, cells were incubated with $100 \mu \mathrm{L}$ culture medium and $10 \mu \mathrm{L}$ MTT (Sigma) $5 \mathrm{mg} / \mathrm{mL}$ in every well for $4 \mathrm{~h}$. MTT reaction was stopped by SDS reagent (10\% sodium dodecyl sulphate (Merck) in $0.01 \mathrm{M} \mathrm{HCl}$ (Merck)) and was incubated overnight. The absorbance was measured by microplate reader (Bio-Rad) at wave length of $595 \mathrm{~nm}$.

\section{Cell cycle distribution}

Propidium iodide (PI) staining kit (Becton Dickinson) was used to analyze DNA content. Cells were seeded in 24-well plates with $5 \times 10^{4}$ within 24-48 h (to yield 60-70\% confluence). Cells were treated with $1 / 2 \mathrm{IC}_{50}$ of sample. After a $24-\mathrm{h}$ treatment, cells were harvested, and the cells were resuspended in PBS, fixed with $70 \%$ ethanol, labeled with PI $(2 \mu \mathrm{g} / \mathrm{mL})$, and incubated at room temperature in the dark for $10 \mathrm{~min}$. DNA content was analyzed using a Flow cytometry (Becton Dickinson) and followed by flowing software (version 2.5.1).

\section{Apoptosis detection}

Apoptotic population was determined by PIAnnexin V assay (Annexin V-FITC Apoptosis Detection Kit Roche). Cells were seeded in 24-well plates with $5 \times 10^{4}$ within $24-48 \mathrm{~h}$ (to yield $60-70 \%$ confluence). Cells were treated with $1 / 2 \quad \mathrm{IC}_{50}$ of sample. After a 24-h treatment, cells were harvested, added with $1 \mathrm{x}$ binding buffer, labeled with PI-Annexin V, and incubated at room temperature in the dark for $5 \mathrm{~min}$. Then the cells suspension was analyzed using a Flow cytometry (Becton Dickinson).

\section{Wound healing assay}

Cells were seeded in each well of 24-well plate with $1 \times 10^{5}$ cells and incubated at $37^{\circ} \mathrm{C}$ in $\mathrm{CO}_{2}$ incubator for $24 \mathrm{~h}$. Thereafter cell were starved by using serum free-medium (containing $0.5 \%$ fetal 
bovine serum) for $24 \mathrm{~h}$. The confluent cell monolayers were wounded by a yellow-tip. After washing once with PBS, the cells were added with DMEM culture medium which contained of $1 / 4 \mathrm{IC}_{50}$ of sample. Time-lapse images were acquired at 0 , 18 , and $24 \mathrm{~h}$. Percent of closured were analyzed by using Image-J software.

\section{Gelatin zymography}

MMP-9 and MMP2 activity was assayed by gelatin zymography. Cells were seeded in each well of 6-well plate with $1 \times 10^{6}$ cells and incubate at $37^{\circ} \mathrm{C}$ in $\mathrm{CO}_{2}$ incubator for $24 \mathrm{~h}$. Cells were incubated with $1 / 4 \mathrm{IC}_{50}$ of sample in serum free-medium for $24 \mathrm{~h}$. The supernatants were collected and subjected to gel electrophoresis on $10 \%$ running gel containing $0.1 \%$ gelatin. The gel were washed in renaturing solution containing $2.5 \%$ Triton $\mathrm{x}-100$ for $30 \mathrm{~min}$, and followed by incubation for $20 \mathrm{~h}$ at $37^{\circ} \mathrm{C}$ with incubation buffer. The gels were stained for $30 \mathrm{~min}$ in $0.5 \%$ commassie brilliant blue and destained with destaining solution $(10 \% \mathrm{v} / \mathrm{v}$ methanol and $5 \% \mathrm{v} / \mathrm{v}$ acetic acid). After that, gel were scanned and documented.

\section{Immunoblotting}

Cells were seeded in $10 \mathrm{~cm}$ cultured dish with $1 \times 10^{6}$ cells and incubate at $37^{\circ} \mathrm{C}$ in $\mathrm{CO}_{2}$ incubator for $24 \mathrm{~h}$. Cells were incubated with $1 / 4 \mathrm{IC}_{50}$ of sample for $24 \mathrm{~h}$. Cell were collected with RIPA buffer (25 $\mathrm{mM}$ Tris- $\mathrm{HCl}$ at $\mathrm{pH} 7.6,150 \mathrm{mM} \mathrm{NaCl}, 1 \% \mathrm{NP}-40$, $1 \%$ deoxycholic acid-Na, $0.1 \%$ SDS, proteases and phosphatase inhibitor cocktail). Protein samples were obtained using Bradford method and were measured by microplate reader (SH-1000, Corona electric), separated by electrophoresis on 7-15\% SDS polyacrylamide gel electrophoresis (PAGE) gels, and electro-transferred onto PVDF transfer membranes (Immobilon, millipore). After blocking with $1 \mathrm{x}$ NET gelatin, the membranes were probed with antibodies for HER2 (sc-52349), p120 (sc13957) and B-actin (sc-47778, Santa Cruz Biotechnologies, Santa Cruz, CA), and Rac-1 (ab 33186, Abcam), then exposed to horseradish peroxidase (HRP)-conjugated secondary anti-mouse (sc-2031, Santa Cruz Biotechnologies, Santa Cruz, CA) or anti-rabbit antibodies (cs-7074P2, Cell signaling). Protein expression was examined using the enhanced chemiluminescence (ECL) system (Amersham).

\section{Statistical analysis}

Data were presented as the mean \pm standard deviation (SD). The statistically significant differences between the control/untreated group and treated groups were analyzed by Student $\mathrm{t}$ test. Mean differences was significant at the $p<0.05$. 


\section{RESULTS}

\section{Cytotoxic assay of FEA}

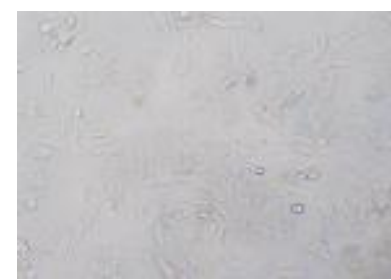

$0 \mu \mathrm{g} / \mathrm{mL}$

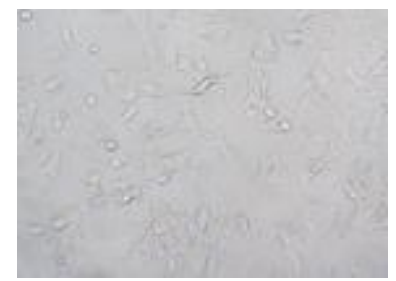

$5 \mu \mathrm{g} / \mathrm{mL}$

A.

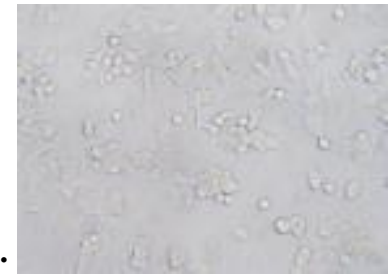

$20 \mu \mathrm{g} / \mathrm{mL}$

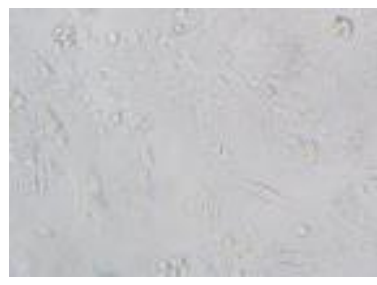

I $\mu g / m L$

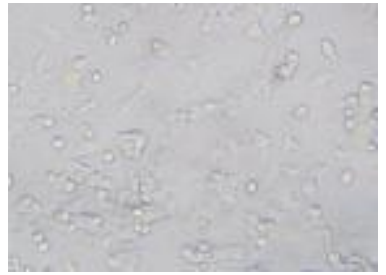

$10 \mu \mathrm{g} / \mathrm{mL}$

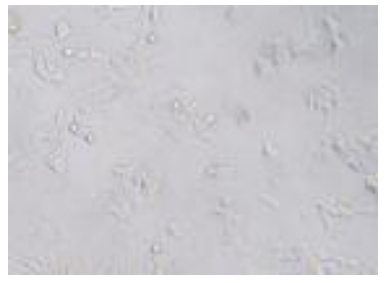

$40 \mu \mathrm{g} / \mathrm{mL}$
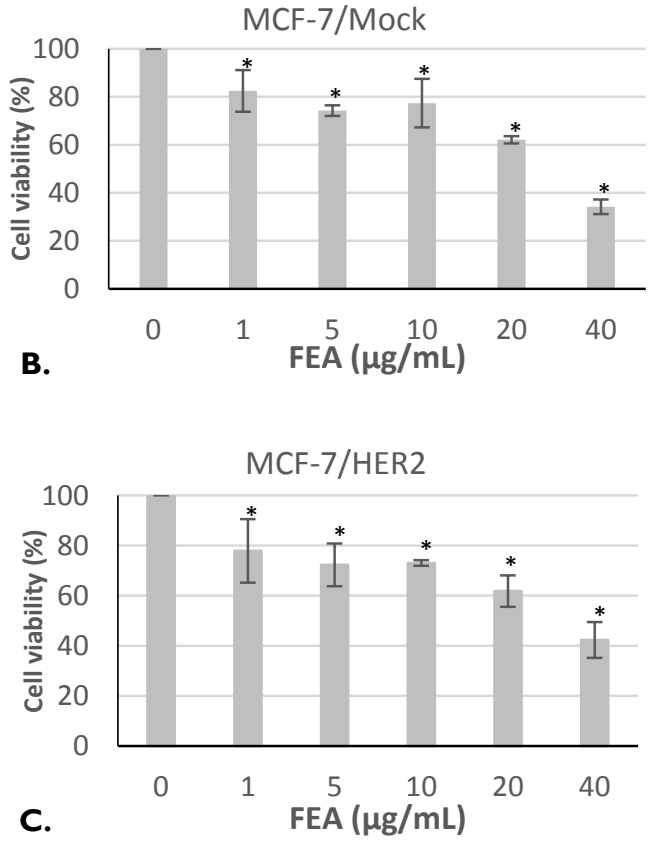

Figure I. Cytotoxic activity of FEA on MCF-7/Mock and MCF-7/HER2. A. Morphology of MCF-7/HER2 cells after FEA $(0-40 \mu \mathrm{g} / \mathrm{mL})$ treatment, B. Cytotoxic activity of FEA on MCF-7/Mock, C. Cytotoxic activity of FEA on MCF7/HER2. Cells were treated with various concentration of samples for $24 \mathrm{~h}$ before assessed by MTT assay. Data was collected from three replications $(* p<0.05)$.

Firstly, it is important to confirm the cytotoxic activities of FEA on both MCF-7/Mock and MCF7/HER2 cells. Treatment of FEA induced the morphologycal alteration of MCF-7/HER2 cells (Fig. 1A) as well as MCF-7/Mock (data not shown). The FEA inhibited MCF-7/Mock and MCF-7/HER2 cells growth with $\mathrm{IC}_{50}$ value $28 \pm 1.3 \mu \mathrm{g} / \mathrm{mL}$ and $33.5 \pm 3.1 \mu \mathrm{g} / \mathrm{mL}$ (Fig. 1B-C) respectively. In order to investigate the mechanism of the cytotoxic effect of FEA, we observed the effect of FEA on cell cycle modulation and induction of apoptosis in the further study. 


\section{Cell cycle and apoptosis modulation of FEA}

\begin{tabular}{c} 
MCF-7/HER2 $(24 \mathrm{~h})$ \\
\hline $0 \mu \mathrm{g} / \mathrm{ml}$
\end{tabular}
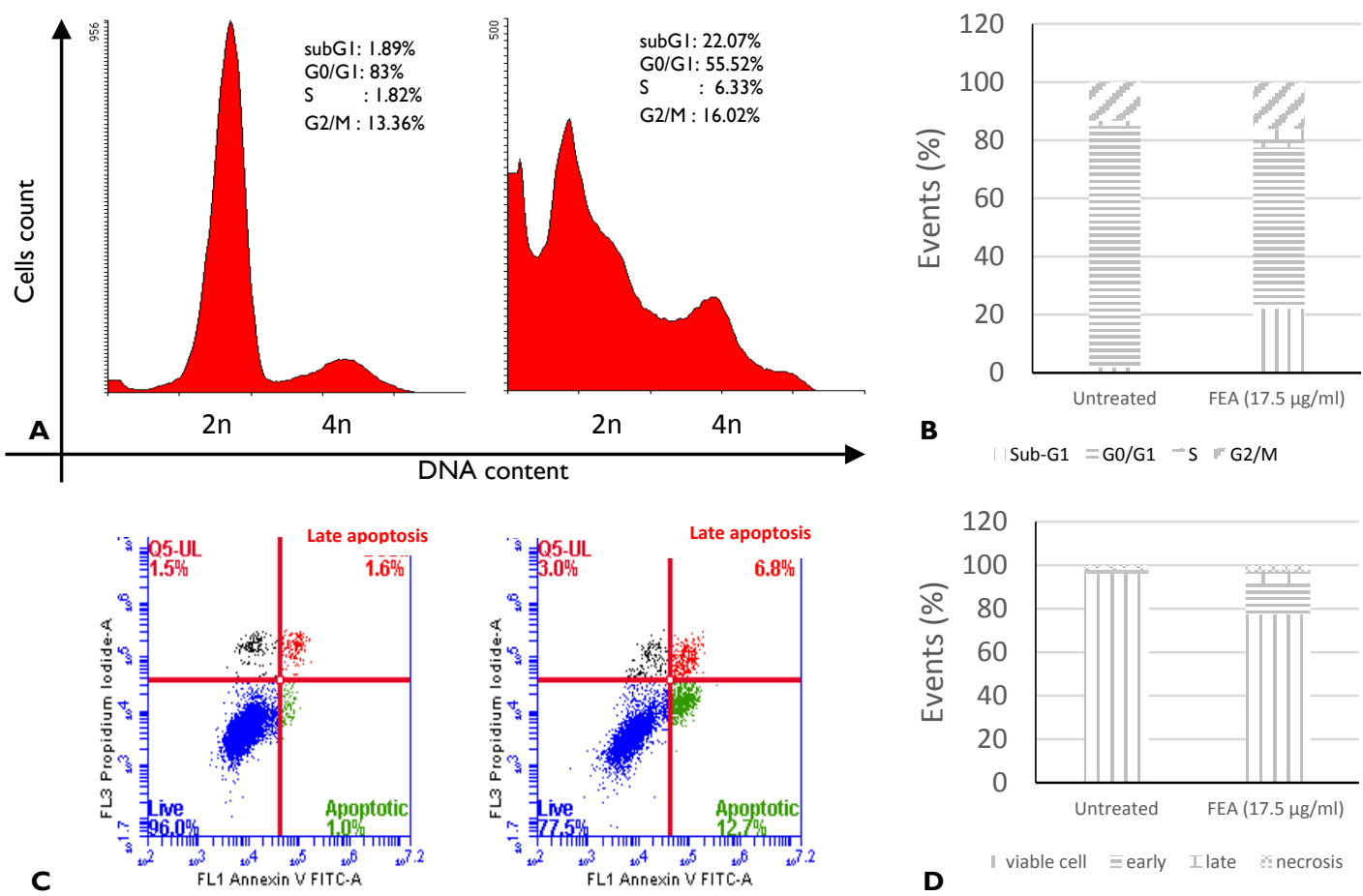

Figure 2. Cell cycle modulation and apoptosis induction of FEA on MCF-7/HER2 cells. Cells were treated with FEA $(17.5 \mu \mathrm{M})$ for $24 \mathrm{~h}$, incubated with PI or PI-Annexin $\mathrm{V}$, measured by using flow cytometry and analyzed by using flowing software according to the method. A. Cell cycle distribution of FEA, B. Graphic of cell cycle distribution of FEA, C. Apoptotic cells distribution of FEA, D. Graphic of apoptotic cells distribution of FEA.

Cell cycle analysis by using flow cytometry showed that treatment of $17.5 \mu \mathrm{g} / \mathrm{mL}$ FEA for $24 \mathrm{~h}$ caused increasing of sub-G1, S-phase and G2/Mphase accumulation until 20.2\%, 4.5\%, and $2.7 \%$ respectively compared to untreated cells (Fig. 2A-B). The high cells accumulation on sub-G1 phase represents the death cells. Nevertheless, to investigate that the death cells were due to apoptosis induction, it should be confirmed with PI-Annexin V flowcytometry analysis. We proved that FEA treatment induced total apoptosis up to $18.4 \%$ compared to untreated cells (Fig. 2C-D). Cytotoxic activity of FEA possibly through inducing of apoptosis and cells cycle accumulation in S-phase and G2/M-phase. 


\section{Inhibition of migration}

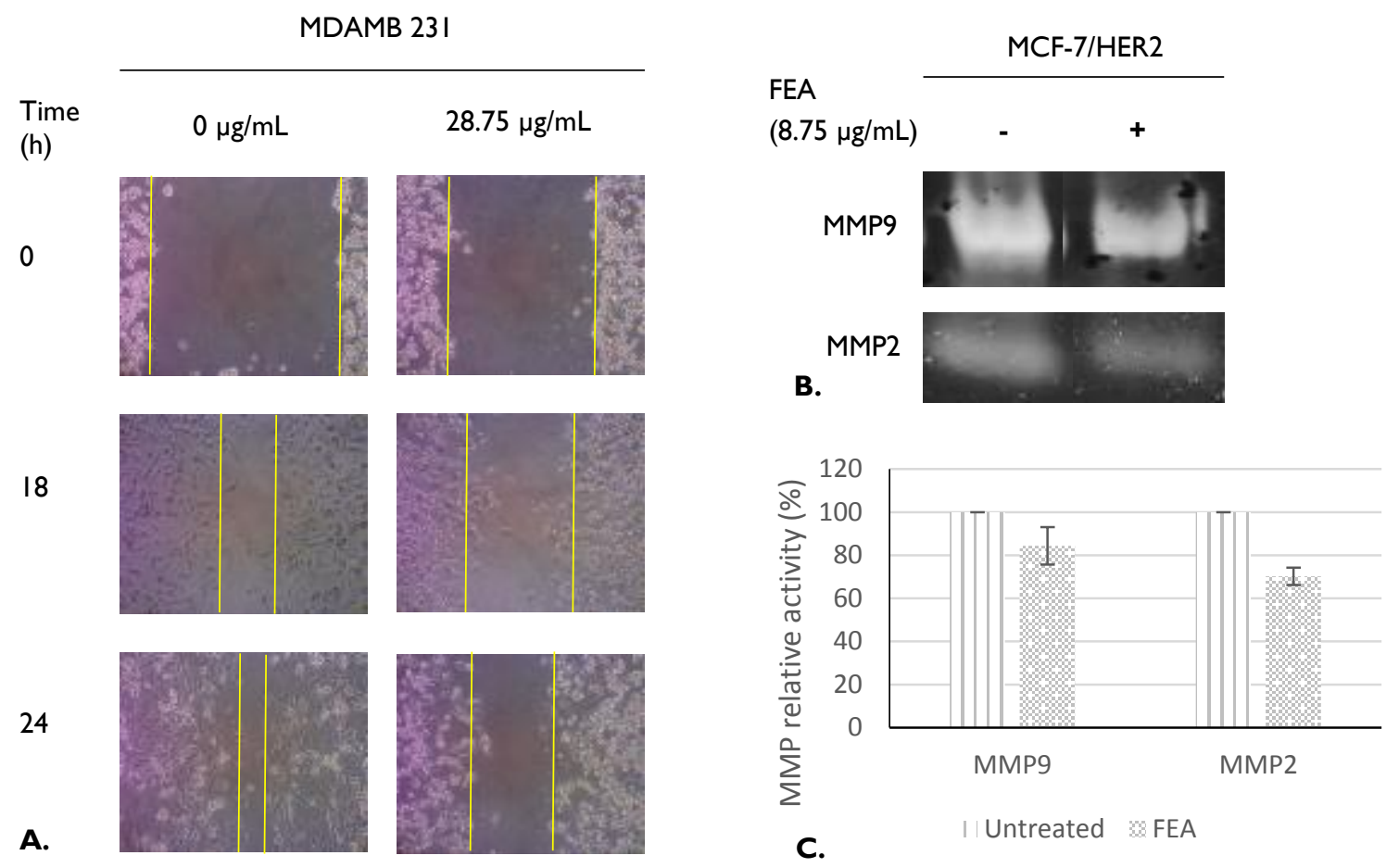

Figure 3. Effect of FEA on migration and invasion on cancer cells. A. wound closured on MDAMB 23। cells. Cells were scratched according to wound healing assay, were treated with $28.75 \mu \mathrm{g} / \mathrm{mL} F E A$ and were photographed at 0 , 18, 24, and $42 \mathrm{~h}$. B. MMP9 and MMP2 activity on MCF-7/HER2. Cells were treated with $8.75 \mu \mathrm{g} / \mathrm{mL}$ FEA for $24 \mathrm{~h}$ and were observed by gelatin zymography. C. Graphic of MMP9 and MMP2 activity. Analysis of activity level of MMP9 and MMP2 was calculated by using image J software, Data was collected from three replications $(* p<0.05)$.

To study whether FEA inhibit migration and invasion, we tested the effect of FEA by wound healing assay and gelatin zymography. We used MDAMB 231 cells as a model for wound healing assay. The result showed that FEA inhibited wound closured on MDAMB 231 cells after 18 and $24 \mathrm{~h}$ incubation (Fig. 3A). MMP2 and MMP9 protein on microenvironment of cancer cells were important markers for migration and invasion cells. Furthermore, we tested the effect of FEA on MMP2 and MMP9 protein expression of MCF-7/HER2 cells based on MMP2 and MMP9 activity by using gelatin zymography. Treatment of FEA decreased MMP2 and MMP9 activity level on MCF-7/HER2 cells until $16 \%$ and $30 \%$ respectively (Fig. 3B-C). Based on the results, FEA inhibited migration and invasion on metastatic cancer cells.

\section{Inhibition of HER2 and Racl protein expression}

The HER2 pathway has an important role on migration and invasion of breast cancer cells. In this study, we observed the effect of FEA on modulation of HER2 protein expression on MCF7/HER2. The result showed that FEA decreased HER2 protein level (Fig. 4). The p120 is coregulator that has an important role on Rac1 activation through HER2 signaling pathway (Johnson, et al., 2010). We also observed the effect of FEA on p120 and Rac1 protein expression that have a role on migration. The MCF-7/HER2 cells showed high level of p120 protein expression but had no effect after FEA treatment (Fig. 4). On the other hand, FEA decreased Rac1 protein level compared to untreated cells (Fig. 4). The FEA decreased HER 2 and Rac1 protein level compared to untreated cells. 


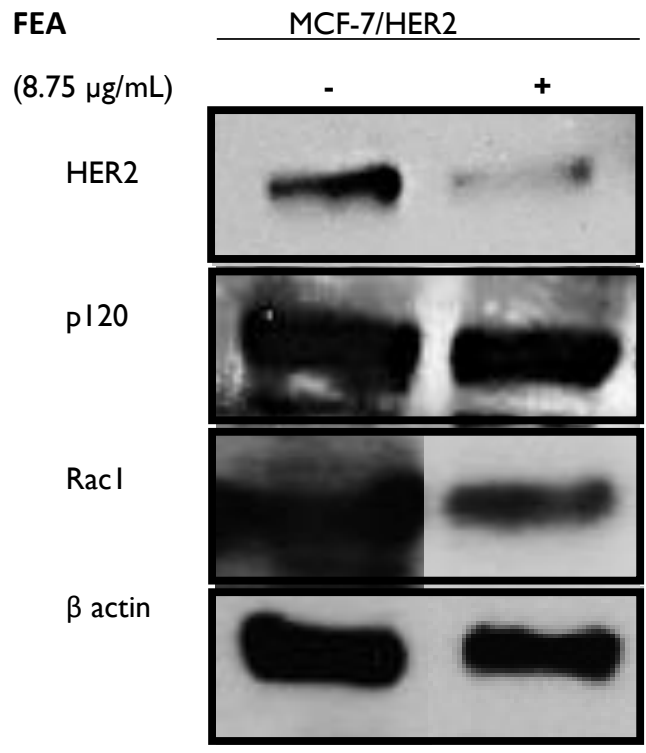

Figure 4. Effect of FEA in HER2, pI20, and Racl protein expression in MCF-7/HER2 cells. Cells were treated with $8.75 \mu \mathrm{g} / \mathrm{ml} \mathrm{FEA}$ for $24 \mathrm{~h}$ and were observed by immunoblotting.

\section{DISCUSSIONS}

The development of antimetastatic agents from natural origin continuously is needed due to the complexity of metastatic feature of cancer cells. Here, we demonstrated $C$. sappan ethyl acetate fraction to inhibit metastatic breast cancer cells proliferation and migration. We found that FEA inhibit MCF7/HER2 cells as well as MCF7/Mock cells (Fig. 1). The differences of the $\mathrm{IC}_{50}$ values were not so wide, indicating that the two different cells character seemed to be responsive to FEA. This phenomenon indicates that FEA is possibly developed to treat breast cancer with high level of HER2.

We also found that FEA performed strong inhibitory effect to the cells migration in MDAMB231 cells. This is an interesting finding since the mature cancer cells tend to be malignant phenotype with metastasis characteristic. MDAMB cells are human metastatic cancer cells through MAPK signaling and exhibit medium HER2 expression (data not shown). However, whether FEA inhibits the cells migration through inhibition of MAPK has to be explored further, even in previous study suggest that brazilein inhibit NF- $\mathrm{KB}$ activation through inhibition of IKK (Hsieh, et al., 2013). Moreover, we found that FEA inhibited HER2 expression indicating that there were possibly a correlation between the inhibitory effect on NF- $\mathrm{KB}$ activation and the lowering HER2 expression since $\mathrm{NF}-\mathrm{kB}$ is known as transcriptional regulatory protein of HER2

Rac-1 and p120 are well known as the key regulators of HER2 overexpression-cells migration (Johnson, et al., 2010). Our findings suggest that FEA more affected to the Rac-1 expression rather than $\mathrm{p} 120$. These findings correlate to the inhibitory effect of cells migration indicating that the inhibitory effect of HER2 expression may correlate to the downregulation of Rac-1 expression but not p120 and contribute to the inhibition of cells migration. This phenomenon is rather unique because it shows different evidence in which Rac-1 expression correlate with p120 level in HER2 expressing cells (Johnson, et al., 2010). Hsieh, et al. (2013) reported that brazilein inhibits migration through inhibition of PI3K and MAPK pathway leading to inhibition of NF- $\mathrm{KB}$ activation. Overexpression HER2 activates NF-kB (Merkhofer, et al., 2010). Rac-1 protein is also activated through PI3K pathway (Ridley, 2015). Further study focusing on Rac-1 activation and expression in correlation with NF- $\mathrm{KB}$ activation will elucidate more detail to these phenomena.

Overall, our finding suggests that FEA is potential to be developed as antimetastatic cancer 
with or without HER2 overexpression. This suggestion is also supported by the fact that FEA treatment decreased the expression of MMP9 and MMP2 significantly. MMP9 and MMP2 are extracellular enzymes secreted by the cells in which the expression levels were regulated by $\mathrm{NF}-\kappa \mathrm{B}$ activation (Hsieh, et al., 2013; Kim, 2010). Our findings provide information the possible intercorrelation among HER-2 status, Rac1, MMP9, MMP2 and NF- $\kappa$ B activation. Further investigation to elucidate this phenomenon is interesting to gain the platform of this fraction to be used in phytomedical practices, especially to cure cancer metastasis in co-chemotherapeutics application.

\section{CONCLUSIONS}

This study confirms that FEA inhibits cell proliferation and migration on MCF-7/HER2 breast cancer cells possibly due to down regulation of MMP9, MMP2, HER2 and Rac1 protein expression.

\section{ACKNOWLEDGMENTS}

We thanks to PUPT 2015-2016 for the project grant.

\section{REFERENCES}

Brix, D.M., Bundgaard Clemmensen, K.K. and Kallunki, T., 2014, When Good Turns Bad: Regulation of Invasion and Metastasis by ErbB2 Receptor Tyrosine Kinase, Cells, 3(I), 53-78,

Brooks, S.A., Lomax-Browne, H.J., Carter, T.M., Kinch, C.E. and Hall, D.M.S., 2010, Molecular Interactions in Cancer Cell Metastasis, Acta Histochem., I I 2(I), 3-25.

Chen, Q.Y., Xu, L.Q., Jiao, D.M., Yao, Q.H., Wang, Y.Y., Hu, H.Z., et al., 20I I, Silencing of Racl Modifies Lung Cancer Cell Migration, Invasion and Actin Cytoskeleton Rearrangements and Enhances Chemosensitivity to Antitumor Drugs, Int. J. Mol. Med., 28(5), 769-776.

Hsieh, C.Y., Tsai, P.C., Chu, C.L., Chang, F.R., Chang, L.S., Wu, Y.C., et al., 2013, Brazilein Suppresses Migration and Invasion of MDA-
MB-23I Breast Cancer Cells, Chem. Biol. Interact., 204(2), I05-II5.

Johnson, E., Seachrist, D.D., DeLeon-Rodriguez, C.M., Lozada, K.L., Miedler, J., Abdul-Karim, F.W., et al., 2010, HER2/ErbB2-induced Breast Cancer Cell Migration and Invasion Require pl20 Catenin Activation of Racl and Cdc42, J. Biol. Chem., 285(3I), 2949I29501.

Kim, B., Kim, S.H., Jeong, S.J., Sohn, E.J., Jung, J.H., Lee, M.H., et al., 2012, Brazilin Induces Apoptosis and G2/M Arrest via Inactivation of Histone Deacetylase in Multiple Myeloma U266 Cells, J. Agric. Food Chem., 60(39), 9882-9889.

Kim, B.S., 2010, Brazilin Inhibits of TPA-induced MMP-9 Expression via the Suppression of NF-KB Activation in MCF-7 Human Breast Carcinoma Cells, J. Food Hyg. Saf. [n.v], [n.p].

Kim, E.C., Hwang, Y.S., Lee, H.J., Lee, S.K., Park, M.H., Jeon, B.H., et al., 2005, Caesalpinia Sappan Induces Cell Death by Increasing the Expression of p53 and P2IWAFI/CIPI in Head and Neck Cancer Cells, Am. J. Chin. Med., 33(3), 405-4l4.

Laksmiani, N.P.L., Susidarti, R.A. and Meiyanto, E., 2015, Brazilein Increases the Sensitivity of Doxorubicin on MCF-7 Resistant Doxorubicin (MCF-7/DOX) Cells through Inhibition of HER-2 Activation, Int. J. Pharm. Pharm. Sci., 7(2), 525-528.

Merkhofer, E.C., Cogswell, P. and Baldwin, A.S., 2010, Her2 Activates NF-kappaB and Induces Invasion through the Canonical Pathway Involving IKKalpha, Oncogene, 29(8), I238-1248.

Nirmal, N.P., Rajput, M.S., Prasad, R.G.S.V. and Ahmad, M., 2015, Brazilin from Caesalpinia sappan Heartwood and Its Pharmacological Activities: A review, Asian Pac. J. Trop. Med., 8(6), 42 I-430.

Nurzijah, Ika, Putri, D.D.P., Rivanti, E. and Meiyanto, E., 2012, Secang (Caesalpinia sappan L.) Heartwood Ethanolic Extract Shows Activity as Doxorubicin Cochemotherapeutic Agent by Apoptosis Induction on T47D Breast Cancer Cells, 
Indones. J. Cancer Chemoprevent., 3(2), 377384.

Ridley, A.J., 2015, Rho GTPase signalling in cell migration, Curr. Opin. Cell Biol., 36, 103-II2.

Tao, L., Li, J. and Zhang, J., 2013, Brazilein, A Compound Isolated from Caesalpinia sappan Linn., InduceGrowth Inhibition in
Breast Cancer Cells via Involvement of GSK-3 $\beta / \beta-C a t e n i n / c y c l i n$ DI pathway, Chem. Biol. Interact., 206(I), I-5.

Tao, L., Li, J. and Zhang, J., 20I I, Brazilein Induced Cells Apoptosis in Human Breast Cancer MCF-7 Cells and Its Action Mechanism, J. Sun Yat-Sen Univ. Med. Sci., 32, 449-453. 